\title{
Oestrogenic activity using a recombinant yeast screen assay (RCBA) in South African laboratory water sources
}

\author{
NH Aneck-Hahn ${ }^{1,3 *}$, C de Jager ${ }^{1,2}$, MS Bornman ${ }^{1}$ and D du Toit ${ }^{3}$ \\ ${ }^{1}$ Andrology, Department of Urology, University of Pretoria, Pretoria, South Africa \\ ${ }^{2}$ Environmental Health, School of Health Systems and Public Health, University of Pretoria, Pretoria, South Africa \\ ${ }^{3}$ Department of Biomedical Sciences, Faculty of Health Sciences, Tshwane University of Technology, Pretoria, South Africa
}

\begin{abstract}
Many chemicals released into the environment are believed to disrupt normal endocrine functions in humans and animals. These endocrine disrupting chemicals (EDCs) affect reproductive health and development. A major group of EDCs that could be responsible for reproductive effects are those that mimic natural oestrogens, known as xeno-oestrogens. A number of in vivo and in vitro screening strategies are being developed to identify and classify xeno-oestrogens, in order to determine whether they pose a health risk to humans and animals. It is also important to be able to apply the assays to environmental samples for monitoring purposes. In South Africa information on the levels of EDCs in water is limited. While establishing the recombinant yeast screen bioassay (RCBA) using the yeast strain Sacchyromyces cerivisiae for oestrogenic activity, problems were experienced with contamination. Four South African laboratory water sources were assessed. From the results it was clear that the water used in the preparation of the medium for the assay was the source of oestrogenic contamination. Care should be taken to eliminate all possible sources of contamination in the test procedures to eliminate the reporting of false positive results. The fact that South African laboratory and surface waters tested positive for estrogenic activity has far reaching implications regarding reproductive and general health.
\end{abstract}

Keywords: endocrine disrupting chemicals, water, yeast screen, oestrogenic activity.

\section{Introduction}

A number of chemicals released into the environment are believed to disrupt normal endocrine function in humans and animals (Colborn et al., 1993; Toppari et al., 1996). These endocrine disrupting chemicals (EDCs) have various endocrine and reproductive effects, believed to be due to their:

- Mimicking effects of endogenous hormones such as oestrogens and androgen

- Antagonizing the effects of normal, endogenous hormones

- Altering the pattern of synthesis and metabolism of natural hormones

- Modifying hormone receptor levels (Soto et al., 1995).

Documented effects on fish, wildlife and evidence from human epidemiology and experimental toxicology have led to an emerging hypothesis that chemicals may be affecting reproduction and development (Krimsky, 2000; Parrott et al. 2001). One major group of EDCs that could be responsible for disruptive reproductive effects, are those that mimic natural oestrogens.

Currently attention is being devoted to the development of in vivo and in vitro screening strategies to identify and classify xeno-oestrogens, in order to determine whether such chemicals pose a hazard to human health (Beresford et al., 2000). The in vitro assays range from simple competitive binding assays, relying solely on the chemical's ability to bind to the oestrogen receptor (Jobling et al., 1995; Shelby et al., 1996), to more complex systems where the chemical binds to and activates the receptor. These latter assay systems include the proliferation of the hu-

* To whom all correspondence should be addressed.

甶 +2712 354-1676; fax: +2712 329-5152;

e-mail: naneckha@medic.up.ac.za

Received 9 September 2004; accepted in revised form 15 December 2004. man breast cancer cell line (MCF-7) (Soto et al., 1995; Soto et al., 1994), vitellogenin gene expression in hepatocyte cultures (Jobling and Sumpter, 1993), and yeast-based assays expressing either rainbow trout (Petit et al., 1997) or human oestrogen receptors (Routledge and Sumpter, 1996). The oestrogen receptor (ER)-mediated chemical activated luciferase gene expression (ER-CALUX) assay uses T47-D human breast adenocarcinoma cells expressing endogenous ER $\alpha$ and $\beta$, which are stably transfected with an oestrogen-responsive luciferase reporter gene (Legler et al., 1999) and the MVLN cells (Gray et al., 2002).

In general, yeast test systems rely on yeast constructs expressing an (human) oestrogen receptor, which upon binding of suited substrates acts as a transcriptional enhancer for oestrogen-responsive DNA element-controlled reporter genes, in most cases bacterial $\beta$-galactosidase. The activity of this enzyme can be determined photometrically by using a chromogenic substrate and may thus serve as a measure for the oestrogenic potency of the sample under investigation (Rehmann et al., 1999).

Short-term assays need to be standardized and validated and applied to identify EDCs and to determine the relative potency for hormonal responses. From the risk assessment point of view it would be very important to apply such tests for environmental monitoring to identify emitters, actual environmental loads and environmental reservoirs of xeno-oestrogenic compounds (Rehmann et al., 1999).

In South Africa the environment in rural and urbanized areas is often contaminated with a complex mixture of toxic compounds originating from industries, agriculture and private households. Many of these pollutants end up in surface waters, such as dams, rivers and eventually the sea (Aneck-Hahn, 2003; De Jager et al., 2002). Toxic contaminants may disturb the biological equilibrium of aquatic ecosystems and be harmful to humans, if they are transmitted to human food or drinking water. In many rural areas in South Africa the only access 
that the communities have to water for drinking and household purposes are boreholes, natural springs and rivers that are in the area. Water being a scarce and valuable resource in South Africa, it is important to examine the oestrogenic activity in the water sources as it could impact detrimentally on the general health of the population.

DDT (a persistent organic pollutant) has been very successfully used for malaria control in South Africa since 1948. Although it was banned for agricultural use in 1976, its use for malaria control continued (Bouwman, 2000). The EDC effect of DDT is well known. In South Africa there is very little information on the EDC levels in water and currently only limited screening methods are in place (Aneck-Hahn, 2003). Most chemical analytical methods are expensive and are not sufficient to identify all the environmental chemicals and to predict a combination of toxicity and bioavailability. One of the cost-effective ways is to first use short-term, relatively inexpensive bioassays to screen the samples for indications of toxic effects and prioritising samples or sample areas for chemical analyses or more intensive studies.

While establishing the recombinant yeast screen bioassay according to Routledge and Sumpter (1996) to measure oestrogenic activity in environmental samples, problems occurred as a result of contamination. Problems were experienced while conducting the assays, with high background absorbance values of the blank (negative control) indicating a source of possible oestrogenic contamination in the assay procedure.

\section{Material and methods}

Various laboratory water sources (SABAX®, Renalcare Services ${ }^{\circledR}$, water processed through the Millipore Aquasoft-Q purification system and water from Renalcare Services ${ }^{\circledR}$ prior to autoclaving) were studied to obtain the least oestrogenically contaminated water.

The sensitivity and reproducibility of the screen were assessed by measuring the response of the yeast to several dilutions of $17 \beta$-estradiol compared to the assay medium containing solvent only (blank).

The Recombinant Yeast Screen Assay (RCBA) for oestrogenic activity (including details of medium components) previously described by Routledge and Sumpter (1996), was used. In this system, yeast cells transfected with the human oestrogen receptor- $\alpha(E R-\alpha)$ gene, together with expression plasmids, containing oestrogen-responsive elements and the lac-Z reporter gene encoding the enzyme $\beta$-galactosidase, were incubated in a medium containing $17 \beta$-estradiol and the chromogenic substrate, chlorophenol red- $\beta$-d-galactopyranoside (CPRG). Active ligands, which bind to the receptor, induce $\beta$-galactosidase $(\beta$ gal) expression and these cause the CPRG (yellow) to change into a red product that can be measured by absorbance.

The assay was carried out according to the standard assay procedure (Routledge and Sumpter, 1996) in a Type II laminar flow air cabinet, to minimise aerosol formation. The media for the assay were made up using the various laboratory water sources. Serial dilutions of $17 \beta$-estradiol (Cat. No. E8875, Sigma) ranging from $1 \times 10^{-8} \mathrm{M}$ to $4.8 \times 10^{-12} \mathrm{M}(2.274 \mu \mathrm{g} / \ell$ to 1.3 $\mathrm{ng} / \ell$ ) were made in ethanol (Cat. No. 27,0741, Sigma-Aldrich) and transferred to a 96 well micro-titre plate (Cat. No. 95029780 , Labsystems). After allowing the ethanol to evaporate to dryness on the assay plate, aliquots $(200 \mu \ell)$ of the assay medium containing the yeast and CPRG were then dispensed into each sample well. Each plate contained at least one row of blanks (assay medium and solvent ethanol) and a standard curve for 17ß-estradiol (Cat. No. E8875, Sigma) ranging from $1 \times 10^{-8} \mathrm{M}$ to $4.8 \times 10^{-12} \mathrm{M}(2.274 \mu \mathrm{g} / \ell$ to $1.3 \mathrm{ng} / \ell)$ which was extended to a concentration of $1.19 \times 10^{-15} \mathrm{M}\left(3.24 \times 10^{-13} \mathrm{~g} / \ell\right)$. The plates were sealed with parafilm (Cat. No. P7793, Sigma) and placed in a naturally ventilated incubator (Heraeus, B290) at $32^{\circ} \mathrm{C}$ for 3 to $6 \mathrm{~d}$. After $3 \mathrm{~d}$ incubation the colour development of the medium was checked periodically at an absorbance (abs) of $540 \mathrm{~nm}$ for colour change and $620 \mathrm{~nm}$ for turbidity of the yeast culture. The absorbance was measured on a Titertek Multiskan MCC/340 (Labsystems) plate reader to obtain data with the best contrast. After incubation the control wells appeared light orange in colour, due to background expression of $\beta$-galactosidase and turbid due to the growth of the yeast. Positive wells were indicated by a deep red colour accompanied by yeast growth. Clear wells, containing no growth indicated lysis of the cells and colour varied. All experiments were performed in duplicate. The following equation was applied to correct for turbidity:

\section{Corrected-value $=$ test abs $(540 \mathrm{~nm})-[$ test abs $(650 \mathrm{~nm})$} - median blank abs (620 nm)]

The $17 \beta$-estradiol standard curve was fitted (sigmoïdal function, variable slope) using Graphpad Prism (version 2.01), which calculated the minimum, maximum, slope, $\mathrm{EC}_{50}$ value and $95 \%$ confidence limits. The detection limit of the yeast assay was calculated as absorbance elicited by the solvent control (blank) plus three times the standard deviation.

\section{Results}

There appeared to be oestrogenic contamination in the blank, as the wells were red in colour after $3 \mathrm{~d}$ incubation. After careful analysis of the data and various experimental elimination procedures it was decided that the most likely cause of the oestrogenic contamination in this case was the laboratory water source. The results showed that of the four sources tested, the Renalcare ${ }^{\circledR}$ water obtained from the plastic bottle prior to autoclaving was the most reliable. The blank remained within the absorbance range of 1.0 to 1.5 (yellow to light orange) between day 3 and day 6 . The other sources all indicated oestrogenic activity between day 3 and day 4 with absorbencies ranging from 0.6 to 2.0 (yellow to dark red) (Fig.1). Despite the necessary precautions, the solvent blank of the Sabax water had a median blank absorbance of 1.2 after $3 \mathrm{~d}$ incubation, instead of being yellow in colour (abs 1.0), it was dark orange-red and by day 4 the absorbance was 2.1 (very red). The autoclaved water (Renalcare 1) had an absorbance of 2.0 (red colour) on day 6 as opposed to the absorbance of 1.4 on day 6 of the "non"-autoclaved water (Renalcare 2) (Fig. 2). The Sabax and Millipore-Q water had absorbencies of above 2.5 (not shown in Fig. 2).

\section{Discussion}

This is not the first report of the unexpected presence of oestrogenic substances in research laboratories leading to confounding results during experiments (Berthois et al., 1986; Miller et al., 1986; Soto et al., 1991; Feldman and Krishnan, 1995). Krishnan et al. (1993) detected oestrogenic activity in distilled water used to prepare culture media. They found that Bisphenol-A had leached from plastic polycarbonate flasks during autoclaving. This is, however, the first report in South Africa of an unexpected presence of oestrogenic activity in laboratory water.

The results from the "non"-autoclaved water (Renalcare 2) appeared to be the most sensitive and reproducible of all the 


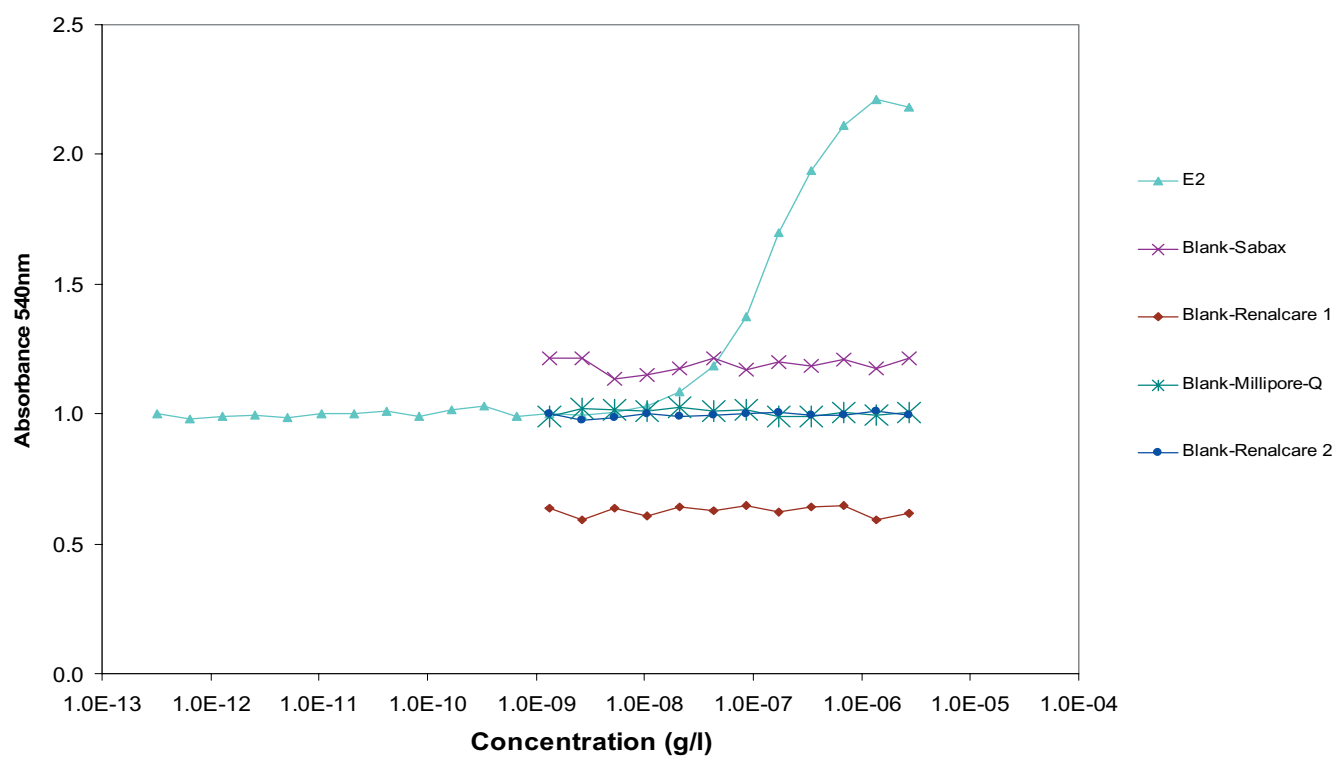

Figure 1

Log concentration of 17- $\beta$ estradiol (E2) serially diluted from $2.72 \times 10^{-6} \mathrm{~g} / \mathrm{l}$ to $3.24 \times 10^{-13} \mathrm{~g} / \mathrm{l}$ and the log concentration of the laboratory water sources (Blank-Sabax, Blank-Renalcare 1, Blank-Millipore- $Q$ and Blank-Renalcare 2) plotted against the absorbance $(540 \mathrm{~nm})$ of the medium after $3 d$ incubation. $\bullet: 17-\beta$ estradiol (E2); $\mathbf{X}$ : Sabax water; $\bullet:$ Renalcare 1 (autoclaved in plastic); $*$ : Millipore-Q; $\bullet$ Renalcare 2 ("non"-autoclaved water)

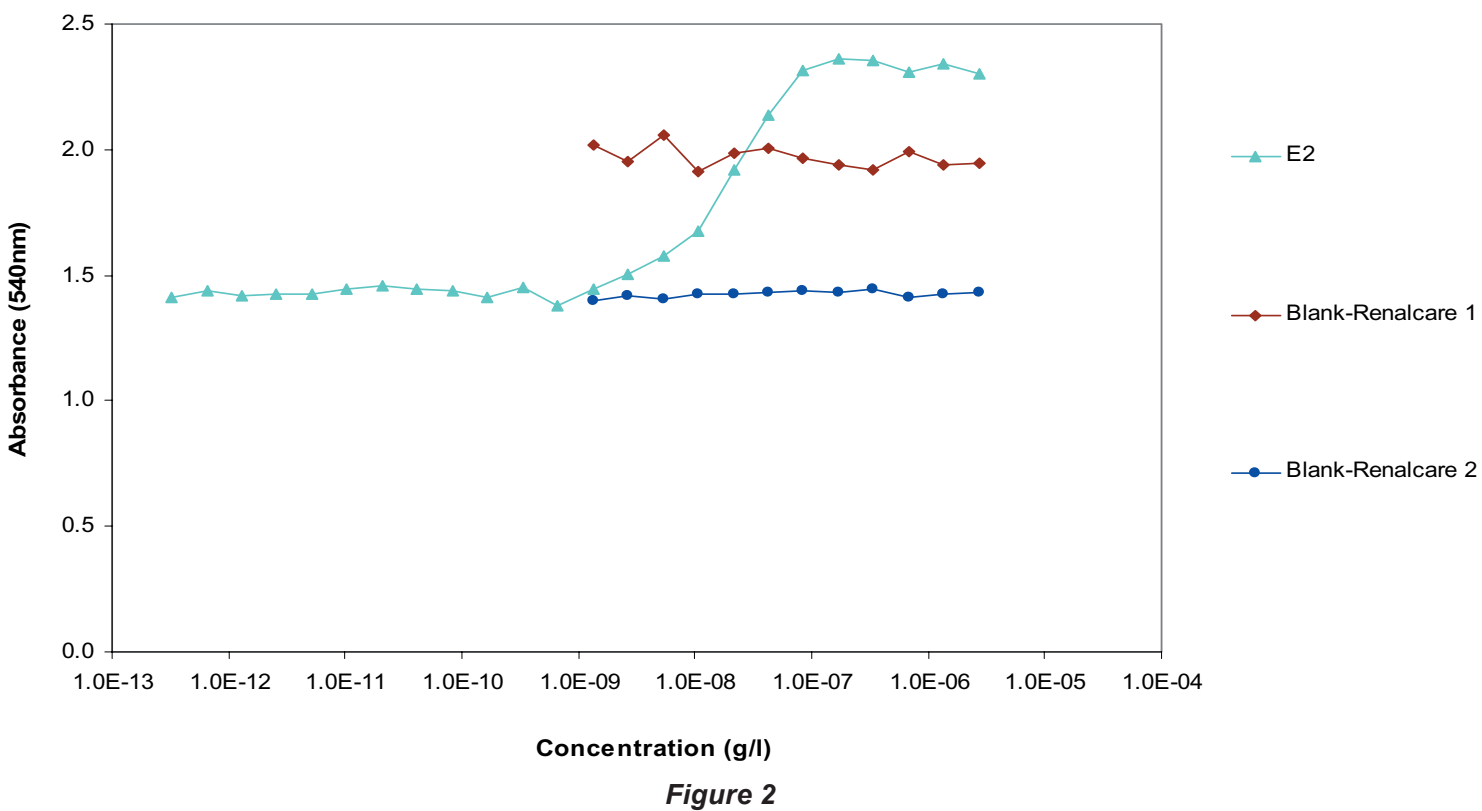

Log concentration of 17- $\beta$ estradiol (E2) serially diluted from $2.72 \times 10^{-6} \mathrm{~g} / \mathrm{l}$ to $3.24 \times 10^{-13} \mathrm{~g} / \mathrm{l}$ and the log concentration of the laboratory water source (Blank-Sabax, Blank-Renalcare 1, Blank-Millipore-Q and Blank-Renalcare 2) plotted against the absorbance $(540 \mathrm{~nm})$ of the medium after $6 \mathrm{~d}$ incubation. $\mathbf{A}: 17-\beta$ estradiol (E2); $\bullet:$ Renalcare 1 (autoclaved in plastic); •: Renalcare 2 ("non"autoclaved water); ( $\mathbf{X}$ : Sabax water; $*$ : Millipore-Q data not shown, absorbencies above 2.5).

laboratory water sources used. Although the blank absorbance was not as low $(<1.0)$ as those in other studies (Routledge and Sumpter, 1996; Harris et al., 1997), the median absorbencies on day 6 were still below 1.5. The most suitable water seems to be the "non"-autoclaved water, which is distilled but not autoclaved before making up media for the assay.

The fact that suitable laboratory water for EDC assays is difficult to obtain in South Africa, is a real issue when attempting to perform not only the yeast screen assay for oestrogenic activity, but also other in vitro EDC assays. After numerous experiments trying to eliminate all possible sources of contamination (e.g. the solvent ethanol, glassware etc.), the water used for the stock cultures and media components appeared to be the source of oestrogenic contamination. Therefore the quality of the water used to make up the assay components is vitally important to the success of the assay.

The yeast-based assay can cover a very wide potency (range at least one millionfold) therefore even a slight contamination by a weak oestrogen can significantly affect the results (Beresford et al., 2000; Harris et al., 1997). Similarly, minimal medium and medium components prepared in glassware contaminated with an oestrogenic chemical will lead to elevated background expression and contaminated chemical stocks will give false positives (Beresford et al., 2000). 
The availability of uncontaminated water in South Africa could well become an issue. It is therefore of vital importance not only in the South African context but also for all assays concerned, that each batch of commercially bottled sterile water should be tested for oestrogenic activity prior making up assay components. These chemicals are so ubiquitous that researchers should be aware and alert to contamination by these chemicals in a laboratory context. This does not only apply to the RCBA in vitro assay, but may also affect other EDC in vitro assays.

It has been shown that oestrogen-mimicking chemicals are present in the aquatic environment. They are also accompanied by other substances, which can disrupt the endocrine system of aquatic fauna by alternative means. Effects that are phenotypically similar to those caused by oestrogens can be induced by anti-androgens and the effects of oestrogens can be blocked by anti-oestrogens. One of the clear implications of this complexity is that chemical analysis on its own will rarely, if ever allow a confidant prediction of endocrine effects (Matthiessen and Sumpter, 1998). Bioassays and biomarkers that integrate these various endocrine-disrupting processes, to achieve a more holistic picture of environmental impacts, are more cost-effective. Detection of activity can then be followed up with toxicity identification.

Suitable systems do exist but methods still need to be validated and standardised. It is recommended that a battery of assays be used to confirm results obtained from testing procedures. Care should be taken to eliminate all possible sources of contamination in the test procedures.

\section{Acknowledgements}

Prof. J Sumpter, Department of Biological Sciences, Brunel University, Uxbridge, London, for the generous donation of the yeast stock culture (Saccharomyces cerevisiae) for the Recombinant Yeast Oestrogen Bioassay (RCBA). Prof. F Comhaire, head of the WHO collaborating Andrology Unit, University Hospital Gent and, founder and spokesman EMR Gent for their technical assistance. The National Research Foundation (NRF) for funding the project.

\section{References}

ANECK-HAHN NH (2003) Screening for Anti-Oxidant Pollutants and Estrogenicity in Drinking Water in Poverty Stricken Areas of South Africa. D. Tech. Thesis, Technikon Pretoria, Pretoria.

BERESFORD N, ROUTLEDGE EJ, HARRIS CA and SUMPTER JP (2000) Issues arising when interpreting results from an in vitro assay for estrogenic activity. Toxicol. Appl. Pharmacol. 162 22-33.

BERTHOIS Y, KATZENELLENBOGEN JA and KATZENELLENBOGEN BS (1986) Phenol red in tissue culture media is a weak estrogen: implications concerning the study of estrogen-responsive cells in culture. Proc. Natl. Acad. Sci. USA 83 2496-2500.

BOUWMAN H (2000) Malaria control and the paradox of DDT. Africa - Environ. Wildlife 8 (4) May 54-56.

COLBORN T, VOM SAAL FS and SOTO A (1993) Developmental effects of endocrine-disrupting chemicals in wildlife and humans. Environ. Health Perspect. 101 (5) 378-384.

DE JAGER C, MYBURGH J, VAN DER BURG B, LEMMEN JG and BORNMAN MS (2002) Estrogenic Contamination of South African River Waters: A Pilot Study. American Waterworks Water Association, April 18-20, Cincinnati, Ohio, USA.

FELDMAN D and KRISHNAN A (1995) Estrogens in unexpected places: Possible implications for researchers and consumers. Environ. Health Perspect. 103 (Suppl 7) 129-133.
GRAY LE JR, OSTBY J, WILSON V, LAMBRIGHT C, BOBSEINE K, HARTIG P, HOTCHKISS A, WOLF C, FURR J, PRICE M, PARKS L, COOPER RL, STOKER TE, LAWS SC, DEGITZ SJ, JENSEN KM, KAHL MD, KORTE JJ, MAKYNEN EA, TIETGE JE and ANKLEY GT (2002) Xenoendocrine disrupters-tiered screening and testing: Filling key data gaps. Toxicol. 181-182 371-382.

HARRIS CA, HENTTU P, PARKER MG and SUMPTER JP (1997) The estrogenic activity of phalate esters in vitro. Environ. Health Perspect. 105 (8) 802-811.

JOBLING S, REYNOLDS T, WHITE R, PARKER MG and SUMPTER JP (1995) A variety of environmentally persistent chemicals, including some phthalate plasticizers are weakly estrogenic. Environ. Health Perspect. 103 (6) 582-587.

JOBLING S and SUMPTER JP (1993) Detergent compounds in sewage are weakly oestrogenic to fish: An in vitro study using rainbow trout (Oncorhynchus mykiss) hepatocytes. Aquat. Toxicol. 27 361-372.

KRIMSKY S (2000) Hormonal Chaos: The Scientific and Social Origins of the Environmental Endocrine Hypothesis. The John's Hopkins University Press, Baltimore, MD.

KRISHNAN AV, STATHIS P, PERMUTH SF, TOKES L and FELDMAN D (1993) Bisphenol-A: An estrogenic substance is released from polycarbonate flasks during autoclaving. Endocrinol. 132 2279-2286.

LEGLER J, VAN DER BRINK C, BROUWER A, MURK AJ, VAN DER SAAG PT, VETHAAK AD and VAN DER BURG B (1999) Development of a stably transfected estrogen receptor mediated luciferase reporter gene assay in the human T47D breast cancer cell line. Toxicol. Sci. 48 55-66.

MATTHIESSEN P and SUMPTER JP (1998) Effects of estrogenic substances in the aquatic environment. In: Fish Ecotoxicology. Switzerland:Birkhäuser Verlag, Basel, 319-335 pp.

MILLER SC, BOTTEMA CDK, STATHIS PA, TOKES LG and FELDMAN D (1986) Unexpected presence of estrogens in culture medium supplements: subsequent metabolism by the yeast Sacchromyces cerevisiae. Endocrinol. 119 1362-1369.

PARROT J, WADE M, TIMM G and BROWN S (2001) An overview of testing procedures and approaches for identifying endocrine disrupting substances. Water Qual. Res. J. Canada 36 (2) 273-291.

PETIT F, LE GOFF P, CRAVEDI JP, VALOTAIRE Y, PAKDEL F (1997) Two complementary bioassays for screening the estrogenic potency of xenobiotics: recombinant yeast for trout estrogen receptor and trout hepatocyte cultures. J. Mol. Endocrinol. 19 321-335.

REHMANN K, SCHRAMM KW and KETTRUP AA (1999) Applicability of a yeast oestrogen screen for the detection of oestrogen-like activities in environmental samples. Chemos. 38 (14) 3303-3312.

ROUTLEDGE EJ and SUMPTER JP (1996) Estrogenic activity of surfactants and some of their degradation products assessed using a recombinant yeast screen. Environ. Toxicol. Chem. 15 (3) 241-248.

SHELBY MD, NEWBOLD RR, TULLY DB, CHAE $\mathrm{K}$ and DAVIS VL (1996) Assessing environmental chemicals for oestrogenicity using a combination of in vitro and in vivo assays. Environ. Health Perspect. 104 (12) 1296-1300.

SOTO AM, JUSTICIA H, WRAY JW and SONNENSCHEIN C (1991) p-Nonylphenol an estrogenic xenobiotic released from "modified" polystyrene. Environ. Health Perspect. 92 167-173.

SOTO AM, CHUNG KL and SONNESCHEIN C (1994) The pesticide endosulfan, toxaphene, and dieldrin have estrogenic effects on human estrogen-sensitive cells. Environ. Health Perspect. 102 (4) 380-384.

SOTO AM, SONNESCHEIN C, CHUNG KL, FERNANDEZ MF, OLEA N and SERRANO FO (1995) The E-screen assay as a tool to identify estrogens - an update on estrogenic environmental pollutants. Environ. Health Perspect. 103 (Suppl. 7) 113-122.

TOPPARI J, LARSEN JC, CHRISTIANSEN P, GIWERCMAN A, GRANDJEAN P, GUILLETTE LJ (Jr.), JÉGOU B, JENSEN TK, JOUNNET P, KEIDING N, LEFFERS H, McLACHLAN JA, MEYER O, MÜLLER J, RAJPERT-DE MEYTS E, SCHEIKE T, SHARPE R, SUMPTER J and SKAKKEBAEK NE (1996) Male reproductive health and environmental xenoestrogens. Environ. Health Perspect. 104 (Suppl. 4) 741-803. 